\title{
Apolipoprotein B100 Measurement
}

National Cancer Institute

\section{Source}

National Cancer Institute. Apolipoprotein B100 Measurement. NCI Thesaurus. Code C120628.

The determination of the apolipoprotein B100 present in a sample. 